\title{
The Mode of Action of Bacilysin and Anticapsin and Biochemical Properties of Bacilysin-resistant Mutants
}

\author{
By M. KENIG, E. VANDAMME AND E. P. ABRAHAM \\ Sir William Dunn School of Pathology, University of Oxford, Oxford $O X X_{1}{ }_{3} R$
}

(Received 5 June 1975; revised 12 November 1975)

\begin{abstract}
SUMMARY
Bacilysin is hydrolysed to L-alanine and anticapsin by suspensions of a bacilysinsensitive strain of Staphylococcus aureus but not by those of a resistant strain derived from it. In contrast, it is hydrolysed by extracts of both strains. Anticapsin is a powerful inhibitor of glucosamine synthetase in extracts of both the bacilysin-sensitive and -resistant strains of Staph. aureus. Bacilysin, by comparison, is a relatively poor inhibitor of glucosamine synthetase in crude extracts when its hydrolysis is inhibited by EDTA. A phenylalanine auxotroph of Staph. aureus readily uses L-alanyl-L-phenylalanine for growth, but a bacilysin-resistant mutant of this strain does not. It is suggested that the antibacterial activity of bacilysin depends on its transport into the organism, its hydrolysis to anticapsin and on inhibition by the latter of glucosamine synthetase, and that bacilysin-resistant mutants are defective in a transport system.
\end{abstract}

\section{INTRODUCTION}

Bacilysin is active against a wide range of bacteria whereas its C-terminal amino acid, anticapsin, has relatively little antibacterial activity (Kenig \& Abraham, 1976; Shah et al., 1970; Rogers, Lomakina \& Abraham, 1965; Walker \& Abraham, 1970). Whitney \& Funderburk (1970) showed that anticapsin was an inhibitor of L-glutamine: D-fructose 6phosphate amidotransferase (glucosamine synthetase, EC.2.6.1 .16) in extracts of Streptococcus pyogenes and Escherichia coli. They also found that inhibition of the synthesis of the hyaluronic acid capsule of Strep. pyogenes by anticapsin was reversed by glutamine. Kenig $\&$ Abraham (1976) reported that glucosamine, $N$-acetylglucosamine and also a wide range of dipeptides were inhibitors of the action of bacilysin against Staphylococcus aureus and E. coli.

Staphylococcus aureus NCrc657 I produces colonies highly resistant to bacilysin (Abraham \& Florey, 1949). Similar behaviour was observed when bacilysin was tested against Salmonella typhi and Candida albicans and the question was raised whether the resistant mutants were defective in a bacilysin transport system (Kenig \& Abraham, 1976).

The experiments described in this paper were intended to provide the reason for the difference in activity between bacilysin and anticapsin and to throw further light on the factors responsible for bacilysin resistance.

\section{METHODS}

Organisms. Staphylococcus aureus NCTC657I (Oxford strain), a bacilysin-resistant strain of Staph. aureus NCrC657I, Escherichia coli B and Candida albicans NCYC597 were as described by Kenig \& Abraham (1976). An auxotrophic mutant, Phe ${ }^{-}$, Leu-, Ile $^{-}$, Met-, derived from Staph. aureus PS80, NCTC9789, was from Dr K. G. H. Dyke, Chemical Micro- 
biology Department, University of Oxford. A bacilysin-resistant strain of this organism was isolated after growth in a modified liquid Kloos medium (Kloos \& Pattee, I965) containing the antibiotic $(7 \cdot 4 \mu \mathrm{M})$.

Media. Brain-heart infusion medium contained $37 \mathrm{~g}$ brain-heart infusion (Oxoid)/1 distilled water. Kloos agar was similar to the amino acid medium (S. agar) described by Kloos \& Pattee (1965) except that it contained no phenylalanine.

Reagents. L-Glutamine, D-glucosamine hydrochloride, and EDTA were obtained from BDH, and D-fructose 6-phosphate disodium salt was from Koch-Light. The samples of bacilysin and anticapsin used were those described by Kenig \& Abraham (1976).

Preparation of extracts of Staph. aureus. Shake-flask cultures of Staph. aureus were prepared in brain-heart infusion medium at $37^{\circ} \mathrm{C}$ and harvested near the end of exponential growth, when the extinction of the culture, read with a Spekker absorptiometer (neutralgrey filter, $\mathrm{H}_{508}$, light path $\mathrm{I} \cdot 5 \mathrm{~cm}$ ), reached 10 . The bacteria (about $\mathrm{I}_{3} \mathrm{~g}$ wet $\mathrm{wt}$ ) were separated by centrifuging at $2700 \mathrm{~g}$ for $30 \mathrm{~min}$, washed twice with $0.8 \% \mathrm{NaCl}$, resuspended in $20 \mathrm{ml} 0.8 \% \mathrm{NaCl}$ and stored at $-20{ }^{\circ} \mathrm{C}$. The staphylococci were disrupted in an X-Press (AB. Biox, Nacka, Sweden). The frozen suspension $(20 \mathrm{ml})$ was passed through the press five times, the whole apparatus being submerged for $20 \mathrm{~min}$ in ethanol at $-25^{\circ} \mathrm{C}$ before each pressing. The disrupted suspension was thawed at $4{ }^{\circ} \mathrm{C}$ and centrifuged $(2700 \mathrm{~g}, 30$ min). The supernatant fluid was removed, the debris washed with $15 \mathrm{ml} 0.8 \% \mathrm{NaCl}$ in the centrifuge, and the two supernatant solutions combined. The resulting extract (about $30 \mathrm{ml}$ ) was used as a crude preparation of glucosamine synthetase.

Assay of glucosamine synthetase. Enzyme activities were measured by the method of Ghosh et al. (1960), with two modifications: I ml of acetic anhydride in acetone (I \%, v/v) was used instead of $0 . \mathrm{I} \mathrm{ml}$ aqueous acetic anhydride $(5 \%, \mathrm{v} / \mathrm{v})$, and dipotassium tetraborate solution $(0.8 \mathrm{M}, \mathrm{pH} 9)$ instead of sodium borate solution $(0.8 \mathrm{M}, \mathrm{pH}$ ) $)$. Each reaction mixture normally contained, in a final volume of $2 \mathrm{ml}: 8.56 \mathrm{~mm} \mathrm{D}$-fructose 6-phosphate disodium salt, I $2 \mathrm{mM} \mathrm{L}$-glutamine, I6.7 mM-Sorensen's phosphate buffer $\mathrm{pH}$ 6.64, and glucosamine synthetase (usually $0.4 \mathrm{ml}$ of the crude enzyme preparation). Some mixtures also contained EDTA and/or bacilysin or anticapsin, in varying concentrations, as described in the text. After $30 \mathrm{~min}$ at $37^{\circ} \mathrm{C}$, the mixture was heated in a boiling water bath for $2 \mathrm{~min}$, cooled, and $0.4 \mathrm{ml}$ withdrawn and assayed for glucosamine 6-phosphate. In each experiment, two control samples, one without enzyme and one without substrates, were assayed in the same way. The extinction reading for the control without substrates, or (with high fructose 6-phosphate concentrations) the sum of the readings for the two controls, was subtracted from the readings obtained for samples of the complete reaction mixtures. Solutions of glucosamine$\mathrm{HCl}(\mathrm{O} \cdot \mathrm{I}$ to $\mathrm{I} \cdot \mathrm{O} \mathrm{mM})$ were assayed simultaneously, to obtain a standard line from the plot of extinction against concentration of glucosamine.

Assay of bacilysin in extracts of Staph. aureus. The bacilysin present in reaction mixtures was assayed by the hole-plate method; the test organism was $E$. coli $\mathrm{B}$, grown on minimal agar (Kenig \& Abraham, 1976). The plates were inoculated with approximately $3 \times 10^{5} E$. coli $\mathrm{B}$ cells/ml agar. Anticapsin showed no activity in this assay at the concentration used.

Immediately after the addition of the extract of Staph. aureus to the reaction mixtures, samples were withdrawn and diluted five times in distilled water before bacilysin assay, the whole process being carried out at $4{ }^{\circ} \mathrm{C}$. After incubation of the reaction mixtures for $30 \mathrm{~min}$ at $37^{\circ} \mathrm{C}$, samples were again assayed. The assay plates were kept at $4{ }^{\circ} \mathrm{C}$ for about $6 \mathrm{~h}$, before overnight incubation at $37^{\circ} \mathrm{C}$. Bacilysin to which no extract had been added was assayed similarly and the inhibition zones compared with those produced by the reaction mixtures. 
In these assays there was no difference between the zone sizes obtained with samples of the zero-time reaction mixtures and those of the controls containing no bacterial extract. It thus appeared that no enzymic inactivation of bacilysin occurred during the assay itself.

Electrophoresis. The products of the incubation of bacilysin with the dialysed extract from Staph. aureus NCTC6571 were examined by electrophoresis on Whatman No. I paper at $70 \mathrm{~V} \mathrm{~cm}^{-1}$ in an apparatus similar to that of Katz, Dreyer \& Anfinsen (I959) in a mixture of $20 \%(\mathrm{v} / \mathrm{v})$ acetic acid and $2 \%(\mathrm{v} / \mathrm{v})$ formic acid, $\mathrm{pH} \mathrm{I} \cdot 8$. Bacilysin, anticapsin, L-alanine and cell-free extract were run simultaneously and spots were visualized by a cadmium-ninhydrin dip.

To identify compounds containing an epoxide group, a sample of the reaction mixture was subjected to electrophoresis for $50 \mathrm{~min}$, the paper dried and a strip cut out to include all the components of the mixture revealed as ninhydrin positive on an adjacent control strip. The first strip was sprayed with $2 \%(w / v)$ sodium thiosulphate, dried, and sewn along the origin of a fresh sheet of paper. After further electrophoresis for 20 min the paper was developed in cadmium--ninhydrin. The components of the reaction mixture formed a diagonal except for those which had reacted with the thiosulphate.

Bioautography. After electrophoresis of the mixture of bacilysin and an extract of Staph. aureus and of bacilysin and anticapsin, at $\mathrm{pH} \mathrm{r} \cdot 8$, the dried paper was placed on minimal agar seeded with $C$. albicans NCYC597. After 30 min the paper was removed and the plate incubated at $28{ }^{\circ} \mathrm{C}$ for $48 \mathrm{~h}$. Both bacilysin and anticapsin are active against C. albicans grown in minimal agar (Kenig \& Abraham, 1976).

Inactivation of bacilysin by Staph. aureus. Bacilysin was added to cultures of Staph. aureus in nutrient broth containing glucosamine, as described by Kenig \& Abraham (1976). Samples removed at intervals were centrifuged, and the concentration of bacilysin in the supernatants determined by hole-plate assays (Kenig \& Abraham, 1976).

In other experiments, bacilysin was mixed at $25^{\circ} \mathrm{C}$ with suspensions of staphylococci prepared from $16 \mathrm{~h}$ resting-phase cultures by the addition of an equal volume of $0.9 \% \mathrm{NaCl}$ to harvested and washed bacteria. The concentration of bacilysin was determined at intervals by hole-plate assays.

\section{RESULTS}

\section{Hydrolysis of bacilysin by sensitive and resistant strains of Staph. aureus}

Inactivation in growing cultures and bacterial suspensions. Addition of bacilysin to a growing culture of Staph. aureus NCTC6571, together with glucosamine to inhibit its effect on bacterial growth (Kenig \& Abraham, 1976), resulted in a fall in bacilysin activity to virtually zero in $8 \mathrm{~h}$ (Fig. I). In contrast, bacilysin lost no significant activity after addition to a bacilysin-resistant strain of Staph. aureus (derived from NCTC657I) under similar conditions.

Comparable results were obtained when bacilysin (final concentration $96 \mu \mathrm{M}$ ) was mixed with suspensions of bacilysin-sensitive and bacilysin-resistant staphylococci. With Staph. aureus NCTC657 I, no detectable bacilysin activity remained after $4 \mathrm{~h}$ and anticapsin appeared in the suspension fluid, whereas with the resistant strain more than $80 \%$ remained after $7 \mathrm{~h}$.

The inactivation of bacilysin appeared to be caused by a cell-bound enzyme. No loss of activity was observed when the antibiotic was added to a bacteria-free supernatant from a culture of Staph. aureus NCTC657I.

Hydrolysis in bacterial extracts. When bacilysin (final concentration $590 \mu \mathrm{M}$ ) was added to a dialysed extract of disrupted Staph. aureus NCrc657I (pH 6.64) kept at $37^{\circ} \mathrm{C}$, hydrolysis of the antibiotic was complete within an hour. After electrophoresis no ninhydrin-positive 


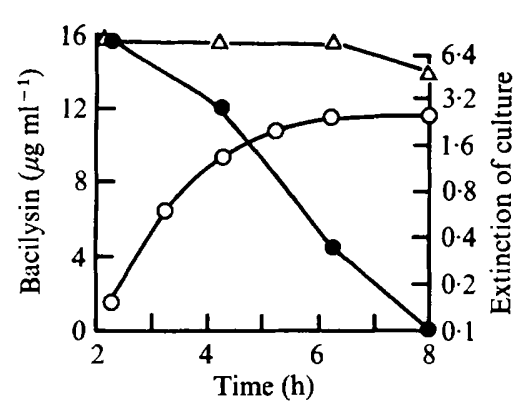

Fig. I

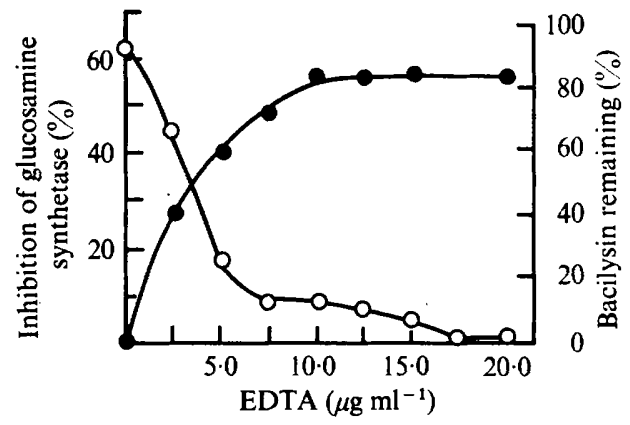

Fig. 2

Fig. I. Inactivation of bacilysin (final concentration $74 \mu \mathrm{M}$ ) by a culture of Staph. aureus growing in nutrient broth at $37^{\circ} \mathrm{C}$ in the presence of $0.8 \mathrm{~mm}$-glucosamine hydrochloride. $O$, Extinction of the culture; activity of bacilysin in the culture; $\Delta$, activity of bacilysin in nutrient broth.

Fig. 2. Effect of EDTA on the stability of bacilysin and the inhibition of glucosamine synthetase in an extract of Staph. aureus NCTC657I. The reaction mixtures were incubated at $37^{\circ} \mathrm{C}$ for 30 min before estimating glucosamine 6-phosphate and bacilysin. In each mixture the initial concentration of bacilysin was $10 \mu \mathrm{M}$. 0 , Bacilysin ( $\%$ of initial concentration); $O$, glucosamine synthesis $(\%$ inhibition).

spot was visible in the position corresponding to bacilysin, but there were two major spots in the positions of alanine and anticapsin respectively. Hydrolysis of bacilysin was not inhibited by L-alanyl-L-phenylalanine in a molar concentration 20 times that of the antibiotic.

The results of two further experiments confirmed that anticapsin was a product of hydrolysis. In the first, anticapsin was detected after electrophoresis by bioautography with $C$. albicans as the test organism. In the second, the paper was sprayed after electrophoresis with sodium thiosulphate. The reaction with the epoxide group of anticapsin resulted in the introduction of a strongly acidic S-sulphonic acid group into the molecule and the formation of a compound with virtually no net charge at $\mathrm{pH}$ I 8 (cf. Rogers et al., I965):<smiles>CC1(C)OC1(C)SS(=O)(=O)[O-]</smiles>

On subsequent electrophoresis in a perpendicular direction alanine again migrated, as expected, towards the cathode, but the compound formed from anticapsin remained at the origin.

To compare the rate of hydrolysis of bacilysin to anticapsin and alanine by an extract of the resistant strain with that by an extract of the sensitive strain, diluted extracts from similar weights of bacteria were incubated with bacilysin in shake-flasks and samples withdrawn at I 5 min intervals. The samples were assayed with Staph. aureus NCTC657I, against which anticapsin is inactive. There was no significant difference in the rates of hydrolysis by the two strains. No significant loss of activity occurred in a solution of bacilysin incubated without extract.

Inhibition of hydrolysis by EDTA. After incubation of bacilysin $(590 \mu \mathrm{M})$ for $\mathrm{I} \mathrm{h}$ at $37^{\circ} \mathrm{C}$ with an extract, containing EDTA (I $\mathrm{mg} \mathrm{ml}^{-1}$ ), of either Staph. aureus NCTC657I or of a bacilysin-resistant strain, insignificant hydrolysis of the antibiotic was found. In portions of the same extracts without added EDTA, hydrolysis was complete. 
Inhibition of glucosamine formation in extracts of bacilysin-sensitive and bacilysin-resistant strains of Staph. aureus

Properties of crude glucosamine synthetase. The initial glucosamine synthetase activities of four preparations of crude enzyme solution from Staph. aureus NCTC657I varied from 0.14 to $0.5 \mathrm{I}$ units $/ \mathrm{ml}$ (the unit being $\mu \mathrm{mol}$ glucosamine formed $/ \mathrm{min}$ ), with excess glutamine and fructose 6-phosphate, at $\mathrm{pH} \mathrm{6.64}$. Extracts stored at $4{ }^{\circ} \mathrm{C}$ lost $50 \%$ of their initial activity in 3 days, but only a further $7 \%$ in the next 4 days.

The $\mathrm{pH}$-activity curve for the enzyme showed a maximum at $\mathrm{pH} 6.9$. Under the conditions of assay the amount of glucosamine formed increased linearly with time during the first $20 \mathrm{~min}$. In the presence of $60 \mathrm{~mm}$-glutamine the rate of glucosamine synthesis increased as the concentration of fructose 6-phosphate was raised from $\mathrm{I} \cdot 25$ to $20 \mathrm{mM}$. Lineweaver-Burk plots gave values of $K_{m}$ which varied from 5.7 to $14.9 \mathrm{~mm}$ for fructose 6-phosphate with the four different extracts.

Inhibition by bacilysin and anticapsin. Under the conditions of assay used, bacilysin and anticapsin appeared to show similar activity as inhibitors of glucosamine synthetase in the crude extract of Staph. aureus. The amount of glucosamine 6-phosphate formed after $30 \mathrm{~min}$ at $37{ }^{\circ} \mathrm{C}$ was reduced by approximately $50 \%$ when either substance was present at a concentration of $12.5 \mu \mathrm{M}$. Since bacilysin was rapidly hydrolysed to anticapsin by the crude extract, EDTA was added to prevent hydrolysis and hence to show whether the dipeptide itself was an inhibitor. When EDTA (final concentration $100 \mu \mathrm{g} \mathrm{ml}^{-1}$ ) was added to the reaction mixtures there was no significant change in the inhibition of glucosamine formation by anticapsin (about $50 \%$ ), whereas the inhibition by bacilysin fell to less than $20 \%$. Inhibition caused by bacilysin ( $10 \mu \mathrm{M}$ ) decreased from $60 \%$ to about $10 \%$ as the concentration of EDTA was raised from o to $7.5 \mu \mathrm{g} \mathrm{ml}^{-1}$, whereas the inhibition by anticapsin (I0 $\mu \mathrm{M}$ ) was unaltered. EDTA alone had no effect on glucosamine synthetase activity.

In the absence of EDTA (Fig. 2) there was virtually complete hydrolysis of bacilysin and the inhibition of glucosamine synthetase by bacilysin was maximal (62\%). At EDTA concentrations of $7.5 \mu \mathrm{g} \mathrm{ml}^{-1}$ and above, inhibition decreased to a relatively low value and most of the bacilysin remained unchanged. A control experiment, in which no bacterial extract was used, indicated that the inactivation of bacilysin ( $16 \%$ ) in the presence of high concentrations of EDTA (Fig. 2) was due mainly to non-enzymic reactions.

Effect of substrate concentration. The inhibitory action of $25 \mu \mathrm{M}$-anticapsin on the synthesis of glucosamine by the crude extract decreased as the concentration of the glutamine substrate was raised (Fig. 3). In contrast, inhibition was unaffected by an increase in the concentration of fructose 6-phosphate. A plot of the data shown in Fig. 3 done in the manner described by Hunter \& Downs (1945) gave an approximately straight line with a slope which was consistent with competitive inhibition and a value for $K_{i} / K_{m}$ of $7 \times 10^{-4}$.

Inhibition of enzyme from bacilysin-sensitive and bacilysin-resistant strains of Staph. aureus. Figure 4 shows the effect of increasing concentrations of anticapsin on the amount of glucosamine formed in extracts of Staph. aureus NCTC657 I and the bacilysin-resistant strain. There appeared to be no significant difference in the inhibition of glucosamine synthetase from these two strains. 


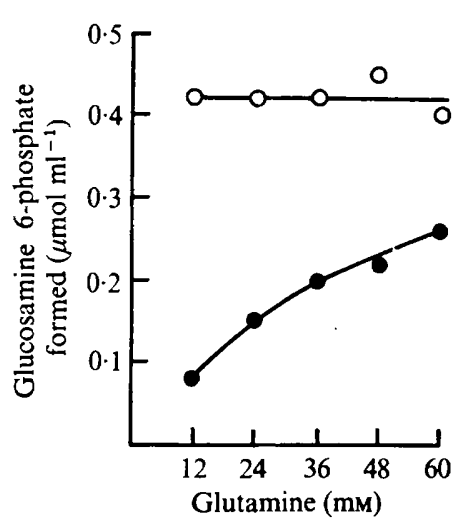

Fig. 3

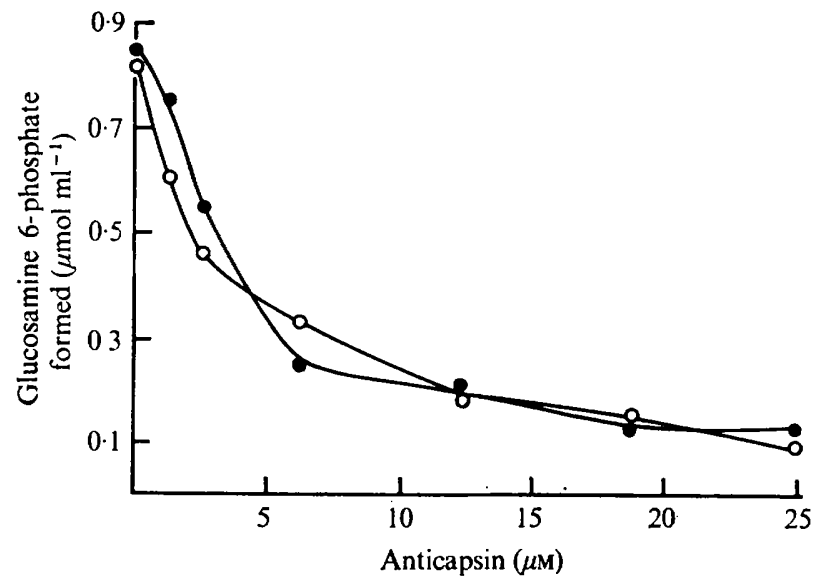

Fig. 4

Fig. 3. Effect of glutamine concentration on the inhibition of glucosamine synthetase by anticapsin $(25 \mu \mathrm{M})$. Determinations were made after incubation for $30 \mathrm{~min}$ at $37^{\circ} \mathrm{C}$ (for details see Methods). 0 , Glucosamine formed in the presence of anticapsin; $\bigcirc$, glucosamine formed in the absence of anticapsin.

Fig. 4. Effect of anticapsin on glucosamine synthetase in an extract of Staph. aureus NCTC657I and of a bacilysin-resistant strain derived from it. Determinations were made after $30 \mathrm{~min}$ at $37^{\circ} \mathrm{C}$ (for details see Methods). $O$, Extract of strain 657I ; 0 , extract of resistant strain.

\section{Utilization of L-alanyl-L-phenylalanine by bacilysin-sensitive and bacilysin-resistant strains} of Staph. aureus auxotrophic for phenylalanine

Staphylococcus aureus PS80 (Phe ${ }^{-}$) grew on Kloos agar containing either L-phenylalanine or L-alanyl-L-phenylalanine $(240 \mu \mathrm{M})$, but bacilysin $(3.7 \mu \mathrm{M})$ gave a much larger zone of inhibition when assayed against this organism on the medium containing phenylalanine (diameter $32 \mathrm{~mm}$ ) than on that containing the dipeptide (diameter $16 \mathrm{~mm}$ ).

When phenylalanine and L-alanyl-L-phenylalanine were tested by the hole-plate method on Kloos agar lacking phenylalanine and seeded with Staph. aureus $\mathrm{PS} 80$ ( $\mathrm{Phe}^{-}$), the holes were surrounded by zones of growth. Equimolar solutions of the amino acid and the dipeptide produced zones of similar diameter (Table I). Zones of growth of comparable size were also produced by phenylalanine with a bacilysin-resistant strain of Staph. aureus derived from PS80 (Phe-), but L-alanyl-L-phenylalanine produced much smaller zones of growth, or none (Table I.)

\section{DISCUSSION}

The findings that anticapsin, the C-terminal amino acid of bacilysin, inhibited glucosamine synthetase from Strep. pyogenes and E. coli (Whitney \& Funderburk, 1970) and that glucosamine and $\mathrm{N}$-acetylglucosamine were powerful inhibitors of the antibacterial action of bacilysin (Kenig \& Abraham, 1976) suggested that a failure of bacterial wall synthesis due to inhibition of glucosamine formation was responsible for the ability of bacilysin to cause lysis of growing staphylococci. The inactivation of bacilysin by a growing culture of Staph. aureus in the presence of glucosamine indicated that the latter did not inhibit transport of the antibiotic through the bacterial membrane.

The glucosamine synthetase in crude extracts of Staph. aureus showed a $\mathrm{pH}$ optimum (6.9) similar to that reported for the enzyme from Neurospora crassa (6.7), though lower 
Table I. Effect of L-phenylalanine and L-alanyl-L-phenylalanine on the growth of Staph. aureus $\mathrm{PS} 80$ (Phe $\left.{ }^{-}\right)$and of a bacilysin-resistant strain derived from it

Holes in seeded Kloos agar plates were filled with solutions of the amino acid or dipeptide. The diameters of the zones of growth were measured after incubation overnight at $37^{\circ} \mathrm{C}$.

$\begin{array}{lccc}\text { Concentration } & & \begin{array}{c}\text { Bacilysin- } \\ \text { sensitive } \\ \text { strain }\end{array} & \begin{array}{c}\text { Bacilysin- } \\ \text { resistant } \\ \text { strain }\end{array} \\ \text { Substance } & 240 & 30 & 32 \\ \text { L-Phenylalanine } & 120 & 26 & 28 \\ & 60 & 21 & 22 \\ \text { L-Alanyl-L-phenylalanine } & 30 & 18 & 18 \\ & 240 & 30 & 19 \\ & 120 & 27 & 14 \\ & 60 & 24 & \text { No zone } \\ & 30 & 21 & \text { No zone }\end{array}$

than that (7.9) for the enzyme from E. coli (Ghosh et al., 1960). Its Michaelis constant for fructose 6-phosphate appeared to be somewhat higher than that of the E. coli enzyme ( $2 \mathrm{~mm}$; Ghosh et al., 1960), but both enzymes were inhibited by anticapsin.

The interpretation of the finding that bacilysin showed an activity similar to that of anticapsin as an inhibitor of glucosamine synthetase in crude extracts of Staph. aureus was complicated by the presence in these extracts of peptidases which hydrolysed bacilysin to anticapsin and L-alanine. The peptidase mainly responsible for the hydrolysis appeared to be metal ion-dependent and to resemble, in this respect and in being intracellular, peptidases of E. coli (Simmonds \& Toye, 1966; Simmonds, 1970; Sussman \& Gilvarg, 1970; Payne, 1972; Brown, 1973). In extracts containing EDTA, bacilysin remained largely unchanged, and under these conditions there was little inhibitory action on glucosamine synthetase. It could thus be concluded that the inhibition of the enzyme in the presence of bacilysin was due largely to the anticapsin formed from the hydrolysis of bacilysin. However, no indication was obtained that inhibition of bacilysin hydrolysis by other dipeptides was responsible for the inhibitory action of the latter on bacilysin activity (Kenig \& Abraham, 1976).

Further experiments are required to determine whether anticapsin and glutamine compete at the same site in glucosamine synthetase and whether the reactive epoxide group in anticapsin can become involved in the formation of a covalent bond with the enzyme. Bates \& Handschumacher (1969) reported that 6-diazo-5-oxonorleucine (DON) irreversibly inactivated glucosamine synthetase from rat liver by alkylation of an active site residue, but that the enzyme could be protected from inactivation by either glutamine or uridine diphospho- $N$-acetylglucosamine (UDPAG). They proposed that glutamine competes with DON for $\alpha$-amino and $\alpha$-carboxyl binding sites, whereas UDPAG binds at a different site and produces a conformational change which prevents alkylation of the enzyme by DON. The epoxide-containing antibiotic phosphonomycin [(-)cis-I,2-epoxypropylphosphonic acid] has been shown to bind covalently to pyruvate-uridine diphospho- $N$-acetylglucosamine transferase by reaction of its epoxide group with the thiol group of a cysteine residue (Hendlin et al., 1969; Strominger, 1969).

The observation that anticapsin is a much more powerful inhibitor of glucosamine synthetase than is intact bacilysin, but shows much poorer antibacterial activity, may be 
accounted for by differences in the transport of these two substances through the bacterial membrane. Similar suggestions have been made to account for the finding that the $\mathrm{N}$ terminal amino acids of the antibiotics, phosphinothricyl-L-alanyl-L-alanine (Bayer $e$ t al., 1972) and L-( $N^{5}$-phosphono)methionine-S-sulphoximinyl-L-alanyl-L-alanine (Pruess et al., I973) show much poorer antibacterial activity than the tripeptides, although both amino acids are effective inhibitors of glutamine synthetase.

The bacilysin-resistant strain of Staph. aureus derived from NCTC657 I produced a glucosamine synthetase which was as sensitive to inhibition by anticapsin as was the synthetase from the parent strain, and extracts of the resistant strain hydrolysed bacilysin to L-alanine and anticapsin as readily as those of the parent strain. Hence, resistance did not appear to be due to mutations in genes coding for these enzymes. On the other hand, the failure of suspensions of intact bacilysin-resistant staphylococci to inactivate the antibiotic, unlike those of the sensitive strain, suggested that resistance was due to mutation in a gene, or genes, coding for proteins involved in a transport system. This view is consistent with the fact that a bacilysin-resistant strain of Staph. aureus derived from strain $\mathrm{Ps} 80\left(\mathrm{Phe}^{-}\right)$utilized L-alanyl-L-phenylalanine for growth much less readily than the parent bacilysin-sensitive strain.

Chmara \& Borowski $(1973 a, b)$ suggested that the antibiotic tetaine, which is probably identical with bacilysin (Kaminski \& Sokolowska, 1973), inhibited murein synthesis in E. coli $\mathrm{KI} 2$ and Staph. aureus and that the inhibition was due to interference with the synthesis of murein precursors at the level of incorporation of L-alanine into UDP- $N$-acetyl-muramic acid. Some of their results also appear to be consistent with the hypothesis that tetaine, like bacilysin, is hydrolysed by an intracellular peptidase to anticapsin and that the latter interferes with the formation of murein at the level of glucosamine synthesis. However, the work described here does not exclude the possibility that bacterial enzymes other than glucosamine synthetase are inhibited by anticapsin or bacilysin.

We are grateful to the Medical Research Council and the Science Research Council for financial support and to the Lilly Research Laboratories for a gift of anticapsin. One of us (E.J.V.) is indebted to Professor J. P. Voets for encouragement and leave of absence from the Laboratory of General and Industrial Microbiology, University of Ghent, Belgium.

\section{REFERENCES}

Abraham, E. P. \& Florey, H. W. (1949). In Antibiotics, vol. 2, p. 1463. Edited by H. W. Florey, E. Chain, N. G. Heatley, M. A. Jennings, A. G. Sanders, E. P. Abraham and M. E. Florey. Oxford: Oxford University Press.

BAtes, C. J. \& HANDSChumacher, R. E. (I969). Inactivation and resynthesis of glucosamine-6-phosphate synthetase after treatment with glutamine analogs. Advances in Enzyme Regulation 7, 183-204.

Bayer, E., Gugel, K. H., Hagele, K., Hagenmaier, H., Jessipow, S., König, W. A. \& Zahner, H. (1972). Stoffwechselprodukte von Mikroorganismen. Phosphinothricin und Phosphinothricyl Alanyl-Alanin. Helvetica chimica acta 55, 224-239.

Brown, J. L. (1973). Purification and properties of dipeptidase M from Escherichia coli B. Journal of Biological Chemistry 248, 409-416.

Chmara, H. \& Borowski, E. (I973a) Antibiotic tetaine, a new inhibitor of murein precursors synthesis in Escherichia coli K-12. Biochemical and Biophysical Research Communications 52, 1381-1387.

Chmara, H. \& Borowski, E. (1973 b). The inhibition of murein synthesis in Staphylococcus aureus by the antibiotic tetaine. Biochemical and Biophysical Research Communications 55, I I 47-I 155.

Ghosh, S., Blumenthal, H. J., Davidson, E. \& Roseman, S. (I960). Glucosamine metabolism. V. Enzymatic synthesis of glucosamine 6-phosphate. Journal of Biological Chemistry 235, 1265-1273. 
Hendlin, D., Stapley, E. O., Jackson, M., Wallick, H., Miller, A. K., Wolf, F. J., Miller, T. W., Chaiet, L., Kahan, F. M., Foltz, E. L., Woodruff, H. B., Mata, J. M., Hernandez, S. \& Mochales, S. (1969). Phosphonomycin, a new antibiotic produced by strains of Streptomyces. Science, New York 166, I 22-123.

Hunter, A. \& Downs, C. E. (1945). The inhibition of arginase by amino acids. Journal of Biological Chemistry $157,427-446$.

Kaminski, K. \& Sokolowska, T. (1973). The probable identity of bacilysin and tetaine. Journal of Antibiotics 26, I 84-185.

Katz, A. M., Dreyer, W. J. \& Anfinsen, C. B. (1959). Peptide separation by two-dimensional chromatography and electrophoresis. Journal of Biological Chemistry 234, 2897-2900.

Kenig, M. D. J. \& Abraham, E. P. (1976). Antimicrobial activities and antagonists of bacilysin and anticapsin. Journal of General Microbiology 94, 37-45.

Kioos, W. E. \& Pattee, P. A. (1965). A biochemical characterization of histidine-dependent mutants of Staphylococcus aureus. Journal of General Microbiology 39, 185-194.

PAYNE, J. W. (1972). The characterization of dipeptidases from Escherichia coli. Journal of General Microbiology 71, 267-279.

Pruess, D. L., Scannell, J. P., Ax, H. A., Kellett, M., Weiss, F., Demny, T. C. \& Stempel, A. (1973). Antimetabolites produced by microorganisms. VII. L- $\left(N^{5}\right.$-Phosphono $)$ methionine- $S$-sulfoximinyl-Lalanyl-L-alanine. Journal of Antibiotics 26, 261-266.

Rogers, H. J., Lomakina, N. \& Abraham, E. P. (1965). Observations on the structure of bacilysin. Biochemical Journal 97, 579-586.

Shah, R., Neuss, N., Gorman, M. \& Boeck, L. D. (1970). Isolation, purification and characterisation of anticapsin. Journal of Antibiotics 23, 613-617.

Simmonds, S. (1970). Peptidase activity and peptide metabolism in Escherichia coli $\mathrm{K}-1$ 2. Biochemistry $9,1-9$.

Simmond, S. \& ToYe, N. O. (1966). Peptidases in spheroplasts of Escherichia coli K-I 2. Journal of Biological Chemistry 24r, 3852-3860.

Strominger, J. L. (1969). Penicillin-sensitive enzymatic reactions in bacterial cell wall synthesis. Harvey Lectures 64, 179-2I3.

Sussman, A. J. \& Gilvarg, C. (1970). Peptidases in Escherichia coli K-12 capable of cleaving lysine homopeptides. Journal of Biological Chemistry 245, 6518-6524.

WalKer, J. E. \& Abraham, E. P. (1970). The structure of bacilysin and other products of Bacillus subtilis. Biochemical Journal $1 \mathbf{1 8}, 563-570$.

Whitney, J. G. \& Funderburk, S. S. (1970). Anticapsin, a new biologically active metabolite. IV. Mechanism of action. Abstracts for the $X$ International Congress for Microbiology, Mexico City, p. IOI. 